THURSDAY, JANUARY 23, 1890.

\section{THE FUTURE INDIAN CIVIL SERVICE EXAMINATIONS.}

$\mathrm{T}^{\mathrm{H}}$ $\mathrm{HE}$ importance of obtaining a satisfactory position for future science candidates in these examinations is now very great. We have not only to consider the need there is that the men selected should represent every side of modern thought and culture, but also to bear in mind the influence of such examinations on the development of education at home. It is unfortunately notorious that candidates offering science in the examinations conducted by the Civil Service Commission stand, as a rule, at a great disadvantage. The marks allotted to science subjects have often been relatively small, and even when outside pressure has secured the allotment of a fair proportion of marks to science, the methods adopted in conducting the examinations have, as has been pointed out in our columns and elsewhere, frequently been such as to prevent good candidates from actually obtaining an equitable proportion of them.

Now as the Commissioners, year by year, deal with thousands, we might say with tens of thousands, of candidates of various types and ages; and as their influence is by no means confined to the actual candidates examined, it is plain that we have in this organization a body whose influence, for good or ill, on education in this country is enormous. Therefore we regard it as most urgent that those who are familiar with this question should press the facts of the present case not only on the attention of the Civil Service Commission, but also at the India Office and on the notice of the public. We are happy to know, indeed, that the subject is being energetically taken up by a number of distinguished graduates of Cambridge. But the forces on the other side are very strong, and past experience of the action of the Commission has made it plain that the representatives of science have a serious task before them.

In their Report for 1888 , the Commissioners have been at some pains to convince the public that their examinations have had a minimum disturbing effect on the ordinary course of education. For example, they show that at several recent examinations for Class I. clerkships in the home services, all, or nearly all, the successful candidates have been men of University education. The Commissioners should carry their investigations somewhat deeper, and ascertain how far these selected candidates represent all classes of University graduates. We have done this so far as opportunity has permitted; and the results of our investigation in the case of the Class I. clerkships (which alone we have at present examined, as it only affects the present question) do not bear out the contention of the Commissioners, but go to show that the examinations concerned are very distinctly calculated either to disturb the course of education or to fail to select men representing all the chief types of University culture.

From our results, which are given below, it is easy to foresee what it is that is to be feared under the coming scheme. For in the competition for Class I. clerkships, the major limit of age, twenty-four, is not far removed from VoL. XLI.-No. 1056 . that about to be adopted for future Indian Civil servants of the highest class. And in them, as we learn will be the case in the future examinations for the Indian service, no limit is placed on the number of subjects that may be selected from those which are examined.

We have before us the results of a number of these competitions held during the last ten or eleven years, and they show, as might have been expected from the scheme of marks, that science men are practically excluded. We have ascertained as far as possible the degrees taken by the successful candidates, and out of thirty we find that twenty-two have taken their degrees in classics, seven in mathematics, and one in natural science; whilst the marks of forty others, whose degrees could not be ascertained, show a similar preponderance of classical men. Now, when it is remembered that many men take honours in science at Oxford, that the number who do so at Cambridge is approaching that of those who take classical honours, and that scholarships are now given for science in considerable numbers at both Universities, it is plain that a scheme which is likely to produce such results as those we have quoted ought on no account to be adopted for the Indian Civil Service. Such a onesided system of selection is not fair to the various classes of candidates, and it is not fair to the dependency which they will be charged to administer. The plain fact is that in the competition for the home services, the marks assigned to classics, mathematics, and science respectively are scarcely fair to mathematics, and very distinctly unfair to science. These branches of learning have been placed upon a far more equal footing at our Universities, and science candidates may fairly claim more equal treatment from the Commissioners in competitions such as those which we are now considering. In the examinations for first-class appointments in the home services, there is the enormous difference of 375 marks against science, out of 1250 in the effective mark values of classics and science. On a recent occasion the difference between the highest and lowest on the list of successful candidates was no more than 158 , and although this is indeed a very exceptional case, it shows how enormous the effect of such a difference may be when the candidates are at all evenly matched.

Such a boycotting of the men of scientific training is deplorable enough in the selecting of men for the home services, but in the case of the future administrators of our Indian dependency it would be far more unfortunate. There, if anywhere, men of every type should play their part in the national work. The Cambridge men of science are doing their best to avert the catastrophe that we fear. We hope they will be supported promptly, universally, and energetically by their scientific brethren, both great and small.

\section{THE SHAN STATES.}

A Thousand Miles on an Elephant in the Shan States. By Hoit S. Hallett. (London and Edinburgh : William Blackwood and Sons, I 889.)

M R. HALLETT'S journeys in Burmah, Siam, and $M$ the Shan States, in search of the best path to connect Burmah with China and Siam, were performed partly by boat, and partly on the back of elephants. 